\title{
ELECTRON DIFFRACTION STUDY OF GASEOUS TETRAHYDROFURAN
}

\author{
H. J. Geise, W. J. Adams and L. S. Bartell $†$ \\ Department of Chemistry, University of Michigan, Ann Arbor, Michigan 48104
}

(Received in USA 20 December 1968; Received in the UK for publication 13 February 1969)

\begin{abstract}
The gas phase molecular structure of tetrahydrofuran has been reinvestigated. Experimental diffraction intensities are well accounted for by a freely pseudo-rotating molecule. The mean value of the pseudo-rotational puckering coordinate was found to be $q_{\mathrm{g}}=0.38 \pm 0.02 \mathrm{~A}$, a value slightly lower than the spectroscopic $q_{0}$ value reported in a far IR study. A definite distinction between free pseudo-rotation and the presence of one or more static puckered conformations could not be made from the electron diffraction intensities. Mean bond lengths and amplitudes of skeletal vibrations were determined and found to be normal.
\end{abstract}

\section{INTRODUCTION}

A FAR IR study ${ }^{1}$ of tetrahydrofuran (THF) has shown that the molecule exhibits the same pseudo-rotational behavior as cyclopentane. From the IR data it was deduced that the amount of puckering $\left(q_{0}=0.44 \AA\right)$ is nearly as large as that proposed for cyclopentane. Furthermore, the properties and conformational aspects of cyclopentane and other saturated 5-membered ring systems have been the object of intensive research during recent years. Therefore, it was thought worthwhile to reinvestigate ${ }^{2}$ the structure of THF by electron diffraction in order to compare its conformational behavior with that of cyclopentane. The structure of cyclopentane will be dealt with in a subsequent paper.

\section{STRUCTURE ANALYSIS AND MODEL CONSIDERATIONS}

The diffraction data were processed and analyzed with an I.B.M. 7090 computer by procedures described previously. $\$$ The experimental reduced intensity, $M(q)$, was obtained from the levelled total intensity, $I_{0}(q)$, in the usual way. Analytical forms of the Hartee-Fock-Slater elastic scattering factors and Heisenberg-Bewilogua inelastic scattering factors were used. Experimental and calculated reduced intensity curves $q M(q)$ are shown in Fig. 1.

The structure determination was achieved by computing several radial distribution functions, ${ }^{4,5} f(r)$ while refining the intensity background function. A Degard damping factor, exp $\left(-0.0015 \mathrm{~s}^{2}\right)$, was used throughout. Corrections were made for integral termination errors, ${ }^{4}$ effects of anharmonicity, ${ }^{6}$ scattering by planetary electrons, ${ }^{5}$ and the failure of the Born approximation. ${ }^{7}$ Values of the index of resolution, $R$, as

- On leave of absence from the Department of Organic Chemistry, University of Leiden, Leiden, The Netherlands.

+ To whom correspondence should be sent.

† The primary digital data representing scattered molecular intensities is available to interested parties on request. 
defined by $R=M_{\exp }(q) / M_{\text {theor }}(q)$ were found to be 1.05 for the 21 and $11 \mathrm{~cm}$ camera distances and 1.0 for the $6.5 \mathrm{~cm}$ distance.

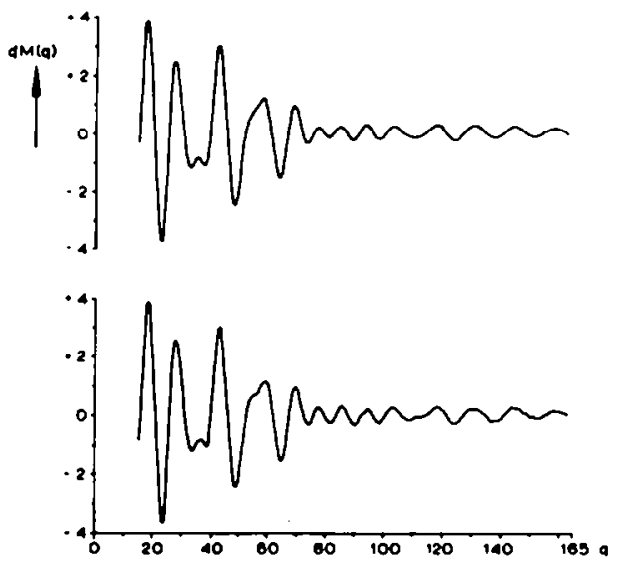

Fio. 1 Theoretical (upper) and experimental (lower) curves of $q M(q)$ for tetrahydrofuran.

The radial distribution curve (Fig. 2) shows that the data are not compatible with a planar model since (a) the $2.4 \AA$ nonbonded peak is closer to the composite $\mathrm{C}-\mathrm{O}$ and $\mathrm{C}-\mathrm{C}$ bonded peak than could occur for a nonpuckered ring and (b) the $\mathrm{O} \cdots \mathrm{H}$, $\mathrm{C} \cdot \mathrm{H}$ composite peak near $3 \AA$ is decidedly split. In view of the infra-red results the

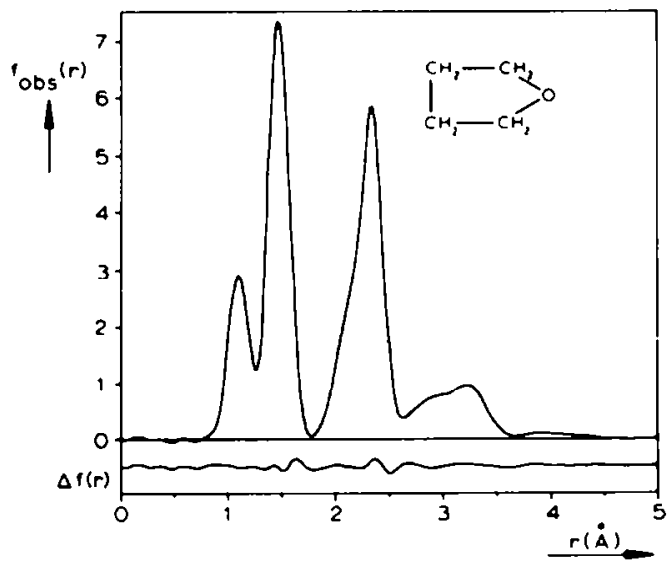

Fig. 2 Plot of the experimental radial distribution function of tetrahydrofuran. The lower curve represents the difference between the experimental and the calculated radial distribution functions.

most logical molecular description seems to be one which incorporates the pseudorotational character of THF. The description adopted is as follows.

Let AB (Fig. 3) designate an axis at right angles to a hypothetical planar conformation serving as a reference plane. Atoms $\mathrm{O} 3$ through $\mathrm{C} 7$ are allowed to move up and down along ares in their respective $\mathbf{A B} j$-planes ( $j$ denotes the number of the atom). An instantaneous displacement parameter, $z_{\hat{r}}$ is introduced which corresponds, in 
Pitzer's model, ${ }^{8}$ to the perpendicular amplitude of atom $j$ from the reference plane. It is taken to be

$$
z_{j}=\left(\frac{2}{5}\right)^{\frac{1}{2}} q \cos \left[2\left(\frac{2 \pi j}{5}+\phi\right)\right], j=1, \ldots 5
$$

in which $\phi$, ranging from 0 to $180^{\circ}$, denotes the phase angle locating the point on the pseudo-rotation pathway and $q$ is the pseudo-radial coordinate which establishes the degree of puckering of the ring from the reference plane. It should be noted that the five vectors $O^{\prime} 3-C^{\prime} 4, C^{\prime} 4-C^{\prime} 5$, etc are convenient reference parameters and do not represent actual bond lengths. To define the geometry of the 'heavy' atom

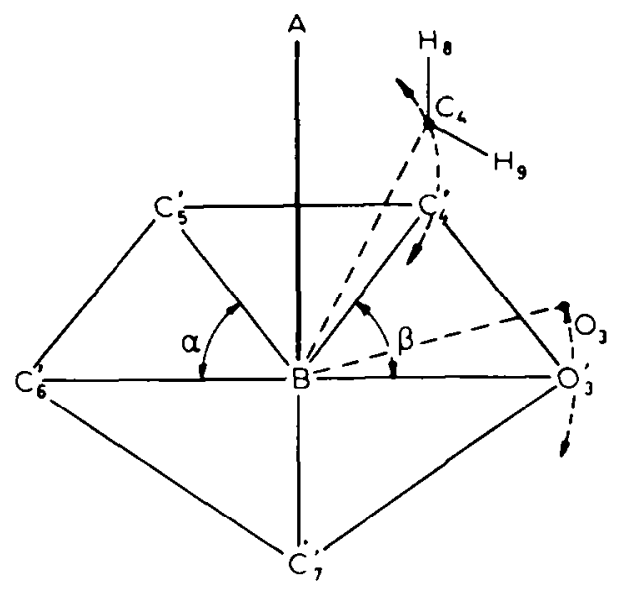

Fic. 3 Model used in describing the geometry of tetrahydrofuran (see text). The atoms H10 and $\mathrm{H} 11$ are attached to $\mathrm{C}, \mathrm{H} 12$ and $\mathrm{H} 13$ to $\mathrm{C} 6$ and H14 and H15 to C7. The carbon atoms C5, C6, C7 (not drawn) move on curved trajectories through the points C'5, C'6 and C7 respectively.

skeleton completely, four more parameters, i.e. the angles $\mathrm{O}^{\prime} 3 \mathrm{~B} \mathrm{C}^{\prime} 4, \mathrm{C}^{\prime} 4 \mathrm{~B} \mathrm{C}^{\prime} 5$, $C^{\prime} 5$ B C'6 and C'6 B C'7 have to be introduced.

In order to make the analysis tractable we made the following assumptions:

I

$$
\mathrm{O}^{\prime} 3-\mathrm{C}^{\prime} 4=\mathrm{O}^{\prime} 3-\mathrm{C}^{\prime} 7=1
$$

$$
C^{\prime} 4-C^{\prime} 5=C^{\prime} 5-C^{\prime} 6=C^{\prime} 6-C^{\prime} 7=m
$$

II

$$
\begin{aligned}
& \mathrm{O}^{\prime} 3 \text { В С } 4=\mathrm{O}^{\prime} 3 \text { В C }^{\prime} 7=\beta \\
& \mathrm{O}^{\prime} 4 \text { В } \mathrm{C}^{\prime} 5=\mathrm{C}^{\prime} 5 \mathrm{~B} \mathrm{C}^{\prime} 6=\mathrm{C}^{\prime} 6 \mathrm{~B} \mathrm{C}^{\prime} 7=\alpha
\end{aligned}
$$

III

$$
O^{\prime} 3 \mathrm{~B}=\mathrm{C}^{\prime} 4 \mathrm{~B}=\text {, etc. }
$$

The crucial, rather artificial, third assumption is made for want of more detailed available information and keeps the model as close as possible to the model adopted for cyclopentane. In the case of cyclopentane this assumption is obviously true. Fortunately, even though it influences the derived bond angles, it turns out that assumption III scarcely affects the determination of $q$. It also reduces the number of adjustable, geometrical parameters $\left(l, m, \alpha, \beta, S_{0}\right)$ to two, because for given $l$ and $m$ 
the other parameters can be computed. That this simplification did not seriously impair the analysis can be inferred from the very good, if not quite perfect, agreement between experimental and calculated intensities (Fig. 1). This model has disadvantages in that all actual molecular distances, including the bonded ones, are dependent upon the pseudo-rotation parameters $q$ and $\phi$.

In order to reduce the dependency of the bond lengths on $\phi$ we constrained the spoke-lengths, $S_{f}$ (i.e. BO3, BC4, etc.) to vary according to:

$$
S_{j}=S_{0}\left(1-k z_{j}^{2}\right)
$$

The variation of $S_{j}$ with $\phi$ implies that the atoms move along a strongly curved noncircular trajectory instead of along the linear trajectory of Pitzer's model. A value of $k \approx 0.65$ gives a minimum dependency of the bond lengths upon $\phi$. Fortunately, this modification of Pitzer's model introduces a negligible difference between $z_{j}$ and the actual distance travelled by ring atoms as a function of $\phi$.

Two possibilities of the motions of the hydrogen atoms during pseudo-rotation have been investigated.

(A) The hydrogens move in a plane defined by the AB-axis and the carbon atom to which they are attached.

(B) They move in a plane which is perpendicular to the plane defined by the bonding $\mathrm{C}$ atom and its two adjacent $\mathrm{C}$ (or $\mathrm{O}$ ) atoms and which bisect the $\mathrm{CCC}$ (or $\mathrm{CCO}$ ) valency angle.

The first possibility gave rise to a distribution of non-bonded $\mathrm{C}-\mathrm{H}$ distances that did not fit the radial distribution curve. No such difficulties were encountered using the second description.

TABLE 1. DISTANCES AND ASSOCLATED ROOT-MRAN-SQUARE AMPLITUDES OF VIBRATION FOUND FOR THF, AND THEIR ESTMMTED STANDARD DEVATHONS (IN A)

\begin{tabular}{|c|c|c|c|}
\hline Distances & $\begin{array}{l}\text { Computed } \\
\text { from model }\end{array}$ & $r_{\theta}$ & 1. \\
\hline $\mathbf{C}-\mathbf{H}$ & $1 \cdot 115$ & $1.115 \pm 0.002$ & $0-079 \pm 0-003$ \\
\hline $\mathrm{C}-\mathrm{O}$ & $1 \cdot 428$ & $1.428 \pm 0-0015$ & $0-051 \pm 0-002^{a}$ \\
\hline $\mathrm{C}-\mathrm{C}$ & 1.536 & $1.536 \pm 0-001_{5}$ & $0-051 \pm 0-002^{\circ}$ \\
\hline$\underset{\text { average }}{\mathrm{O} \cdot \mathrm{H} / \mathrm{C}} \cdot \mathrm{H}$ & $2 \cdot 154$ & $2 \cdot 154 \pm 0.02$ & $0.113 \pm 0-01$ \\
\hline $\begin{array}{c}\mathrm{C} \cdots \mathrm{C} / \mathrm{C} \cdots \mathrm{O} \\
\text { average }\end{array}$ & $2 \cdot 371$ & $2.371 \pm 0.001_{s}$ & $0.075 \pm 0.003$ \\
\hline long $\mathbf{O} \cdots \mathbf{H} / \mathrm{C} \cdots \mathbf{H}$ & $2 \cdot 914$ & $2.905 \pm 0.02$ & $0.156 \pm 0.01_{s}$ \\
\hline long $\mathrm{O} \cdots \mathrm{H} / \mathrm{C} \cdots \mathrm{H}$ & $3 \cdot 270$ & $3.266 \pm 0.01$ & $0.132 \pm 0.01$ \\
\hline
\end{tabular}

- $K \mathrm{C}-\mathrm{O})$ and $(\mathrm{C}-\mathrm{C})$ taken to be identical in refinement.

The first peak in $f(r)$ represents the $\mathrm{C}-\mathrm{H}$ bond. The second is a composite peak containing the $\mathrm{C}-\mathrm{O}$ and $\mathrm{C}-\mathrm{C}$ bond distances. The parameters $l$ and $m$ (see assumption $I$ ) are chosen such that the computed bond distances, averaged over all values of $\phi$, are equal to the ones found experimentally. The third peak is also composite, representing the spectrum of $\mathrm{O} . \mathrm{H}, \mathrm{C} \ldots \mathrm{H}, \mathrm{C} \ldots \mathrm{O}$ and $\mathrm{C} \ldots \mathrm{C}$ non-bonded distances. 
Calculations show that the average of the $\mathrm{C} \cdot \mathrm{C}$ and $\mathrm{C} \cdot \mathrm{O}$ distances is nearly independent of $\phi$ and that this a verage provides the key to the pseudo-rotational parameter q. Also, the steep trailing edge of this non-bonded peak suggests at most a small spread in $\mathrm{C} \cdot \mathrm{O}$ and $\mathrm{C} \cdot \mathrm{C}$ non-bonded distances and agrees very well with the adopted model. It is of interest to note that, in this model, the $\mathrm{CCC}, \mathrm{CCO}$ and $\mathrm{COC}$ valency angles vary during pseudo-rotation in such a way as to account for the constancy of the composite non-bonded peak position. Finally, the region between $2.7 \AA$ and

TABLE 2. SOME EXPERMENTAL DATA CONCERNING THE INTENSITIES AND R.M.S. DEVIATHNS BETWBEN EXP. AND CALCULATED INTENSTTIES

\begin{tabular}{crc}
\hline$q$-range & $\begin{array}{c}\text { camera } \\
\text { distance in cm }\end{array}$ & $\begin{array}{c}\text { r.m.s. in } p p \text { thousand } \\
\text { of the intensities }\end{array}$ \\
\hline $16-67$ & $21.048 \pm 0-003$ & 1.67 \\
$31-110$ & $11.115 \pm 0-002$ & 1.20 \\
$65-164$ & $6.585 \pm 0-002$ & $0-89$ \\
\hline
\end{tabular}

$3.5 \AA$ is composed of the long $\mathrm{H} \cdot \mathrm{O}$ and $\mathrm{H} \cdot \mathrm{C}$ distances (e.g. $\mathrm{H} 8 \cdot \mathrm{C}$, $\mathrm{H} 11 \cdots \mathrm{O}$, etc) and provides a check on the consistency of the model.

Distances obtained from a least squares refinement of the $f(r)$-curve were used as a starting point for a least squares fit of the intensities. The converged set of distances and their associated root-mean-square amplitudes are found in Table 1. Standard deviations in the intensities for the three camera distances are given in Table 2. The commonly used error matrix based on a diagonal weight matrix $P$ and a least squares fit of intensities, and defined by

$$
\mathbf{M}=\mathbf{B}^{-1} \mathbf{V}^{\prime} \mathbf{P V} /(\mathbf{n}-\mathbf{m})
$$

is given in Table 3. Its principal utility is in deducing correlations among the structure parameters. Correlations among the observations as inferred from the autocorrelation function of intensity residuals were significant and invalidate the above relation.

TABLE 3. ERROR MATRIX $\left(\times 10^{7}\right)$ POR TETRAHYDROFURAN, IN $\AA^{2}$

\begin{tabular}{|c|c|c|c|c|c|c|c|c|}
\hline $\begin{array}{c}\text { peak } \\
\text { param. }\end{array}$ & $r(C-H)$ & $r\left(C^{2}-O\right)$ & $(\mathrm{C}-\mathrm{C})$ & $r\left[\begin{array}{c}3 b \\
\mathrm{O} \cdot \mathrm{C} \\
\mathrm{C} \cdot \mathrm{C}\end{array}\right]$ & $r\left[\begin{array}{l}\mathrm{O} \cdot \mathrm{a} \\
\mathrm{C} \cdot \mathrm{H}\end{array}\right]$ & $r\left[\begin{array}{c}\mathrm{Ob} \cdot \mathrm{H} \\
\mathrm{C} \cdot \mathrm{H}\end{array}\right]$ & $\stackrel{1}{1}$ & $l\left[\begin{array}{l}\mathrm{C}-\mathrm{O} \\
\mathrm{C}-\mathrm{C}\end{array}\right]$ \\
\hline & $9 \cdot 2$ & $\begin{array}{l}0.9 \\
3.0\end{array}$ & $\begin{array}{r}0.8 \\
-0.5 \\
2.8\end{array}$ & $\begin{array}{r}-0.1 \\
-0.1 \\
-0.1 \\
3.5\end{array}$ & $\begin{array}{r}4.7 \\
2.8 \\
2.6 \\
-1.7 \\
875.0\end{array}$ & $\begin{array}{r}0.9 \\
1.0 \\
1.0 \\
-2.0 \\
344.2 \\
335.1\end{array}$ & $\begin{array}{r}0.1 \\
1.0 \\
0.6 \\
-1.0 \\
3.8 \\
1.3 \\
8.6\end{array}$ & $\begin{array}{r}-0.9 \\
1.8 \\
-2.1 \\
0.0 \\
-1.0 \\
-1.0 \\
-0.2 \\
4.4\end{array}$ \\
\hline
\end{tabular}

- Based on 149 data interpolated from 327 raw data points. For significance of error matrix see $\mathrm{K}$. Hedberg and M. Iwasaki, Acta Cryst. 17, 529 (1964). 
In order to take these into account, crudely, it seems advisable to multiply the matrix elements by a factor of about three. Standard errors reported in Table 1 include this extra factor. The rms-deviation between the final experimental and theoretical $f(r)$ curves was 0.03 or $0.4 \%$ of the highest peak. Similarly, the largest discrepancy outside the region of physical features $(0.8 \AA \geqslant r \geqslant 4.3 \AA)$ was $0.5 \%$.

\section{DISCUSSION}

Bond lengths obtained in this study do not deviate significantly from those normally found for $\mathrm{C}-\mathrm{H}, \mathrm{C}-\mathrm{O}$ and $\mathrm{C}-\mathrm{C}$ bonds, nor do their rms amplitudes.

The best agreement between experimental values and model calculations was obtained with the following parameter set:

$k=0.65 ; q=0.38 ; l=1.432_{s} ; m=1.546_{s} ;$ from which it follows that

$$
\alpha=74 \cdot 5_{2}^{\circ} \text { and } \beta=68 \cdot 2_{2}^{\circ} \text {. }
$$

Table 4 gives typical geometrical features computed for a pseudo-rotating THF molecule.

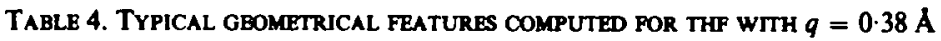

\begin{tabular}{|c|c|c|c|c|c|c|}
\hline Distances & $\begin{array}{l}\text { range over all } \\
\text { conformations }\end{array}$ & $\begin{array}{l}\text { average over } \\
\text { all conformations }\end{array}$ & \multicolumn{2}{|c|}{$\underset{\text { symmetry }}{\mathrm{C}_{\mathrm{z}}}$} & \multicolumn{2}{|c|}{$\begin{array}{c}\mathrm{C}_{2} \\
\text { symmetry }\end{array}$} \\
\hline $\mathbf{C}-\mathbf{H}$ & $1 \cdot 115$ & $1 \cdot 115$ & \multicolumn{2}{|l|}{$1 \cdot 115$} & \multicolumn{2}{|l|}{$1 \cdot 115$} \\
\hline $\mathrm{C}-\mathrm{C}$ & $1.534-1.539$ & 1.536 & \multicolumn{2}{|l|}{1.538} & \multicolumn{2}{|l|}{1.535} \\
\hline $\mathrm{C}-\mathrm{O}$ & $1.425-1.430$ & $1 \cdot 428$ & \multicolumn{2}{|l|}{1.430} & \multicolumn{2}{|l|}{1.426} \\
\hline & $2 \cdot 104-2 \cdot 108$ & $2 \cdot 106$ & \multicolumn{2}{|l|}{$2 \cdot 108$} & \multicolumn{2}{|l|}{$2 \cdot 105$} \\
\hline C $\mathrm{H}$ & $2 \cdot 199-2 \cdot 204$ & $2 \cdot 202$ & \multicolumn{2}{|l|}{$2 \cdot 203$} & \multicolumn{2}{|l|}{$2 \cdot 202$} \\
\hline $\mathrm{O} 3 \mathrm{C5}$ & $2 \cdot 336-2 \cdot 392$ & & $2 \cdot 355$ & \multirow{3}{*}{$2 \cdot 370_{5}$} & $2 \cdot 373$ & \\
\hline \multirow{2}{*}{$\begin{array}{ll}\text { C4 } & \text { C6 } \\
\text { C4 } & \text { C7 }\end{array}$} & $2 \cdot 376-2 \cdot 432$ & $2 \cdot 371$ & $2 \cdot 426$ & & $2 \cdot 381$ & \multirow{2}{*}{$2 \cdot 370_{5}$} \\
\hline & $2 \cdot 290-2 \cdot 344$ & & $2 \cdot 290 \mathrm{~J}$ & & $2 \cdot 344]$ & \\
\hline O3 H10 & $2.795-3.303$ & & \multicolumn{2}{|l|}{3.2597} & \multicolumn{2}{|l|}{3.296 ] } \\
\hline O3 H11 & $2 \cdot 795-3 \cdot 303$ & & \multicolumn{2}{|l|}{2.949} & \multicolumn{2}{|l|}{2.894} \\
\hline C4 H12 & $2.836-3.354$ & $\int 2.914$ & $3 \cdot 198$ & & \multirow{2}{*}{\multicolumn{2}{|c|}{$\begin{array}{l}2.850 \\
3.349\end{array}$}} \\
\hline C4 H13 & $2 \cdot 836-3.354$ & & \multicolumn{2}{|l|}{$3 \cdot 198$} & & \\
\hline C4 $\mathrm{H} 14$ & $2 \cdot 736-3.272$ & $3 \cdot 270$ & $2 \cdot 750$ & $3 \cdot 251$ & $3 \cdot 193$ & $3 \cdot 294$ \\
\hline C4 H15 & $2 \cdot 736-3 \cdot 272$ & & \multicolumn{2}{|l|}{$3 \cdot 261$} & \multicolumn{2}{|l|}{3.039} \\
\hline C5 $\mathrm{H} 14$ & $2 \cdot 858-3.367$ & & \multicolumn{2}{|l|}{3.017} & \multicolumn{2}{|l|}{3.339} \\
\hline C5 H15 & $2 \cdot 858-3 \cdot 367$ & & \multicolumn{2}{|l|}{$3 \cdot 341]$} & \multicolumn{2}{|l|}{$2 \cdot 914$} \\
\hline Valency angles & & torsional angles & legrees ( & abs. valu & & \\
\hline CCC $101 \cdot 5-104 \cdot 4$ & & $\mathrm{C}-(\mathrm{O}-\mathrm{C})-\mathrm{C}$ & $1.0-40$ & & & \\
\hline CCO $104.0-107.5$ & & $\mathrm{O}-(\mathrm{C}-\mathrm{C})-\mathrm{C}$ & $0.9-37$ & & & \\
\hline COC $106.4-110.6$ & & $\mathrm{C}-(\mathrm{C}-\mathrm{C})-\mathrm{C}$ & $0-0-35$ & & & \\
\hline
\end{tabular}

The estimated standard error of $0.02 \AA$ in the pseudo-rotation parameter $q_{g}=0.38$ stems almost entirely from the uncertainty in the non-bonded distances and is insensitive, to a large extent, to the assumptions made. The value obtained by electrondiffraction is slightly lower than the one found by far IR spectroscopy $\left(q_{\mathrm{R}}=0.44 \AA\right)$. 
This may in part be due to the difference in operational definitions of $q$. In IR studies a $q_{0}$ effective value is found while in electron-diffraction a value $q_{g}$ is obtained corresponding to the center of gravity of the probability distribution in $q$. This potential reason for a difference is being examined critically in the concurrent study of cyclopentane.

The amplitude of puckering is somewhat smaller than that found in cyclopentane. ${ }^{9}$ This is understandable in terms of the larger force constant for $\mathrm{COC}$ valency angle deformation and of the smaller barrier to internal rotation around $\mathrm{C}-\mathrm{O}$ bonds in the THF.

Unfortunately, the interesting question as to whether the THF molecules are present in a single conformation or whether they exhibit free pseudo-rotation, could not be answered satisfactorily by electron-diffraction. Some indications favoring pseudorotation are discussed below. The set of computed long $\mathrm{O} \cdots \mathrm{H}$ and $\mathrm{C} \cdots \mathrm{H}$ nonbonded distances as a function of $q$ can be divided into two subgroups. The one ranging from 2.7-3.05 $\AA$, the other ranging from 3.1-3.4 $\AA$; the latter subgroup is more heavily populated and the distances therein are closer together. Accordingly, the experimental $f(r)$ in the region $2.7-3.5 \AA$ can be described by two Gaussian peaks, one at $2.91 \AA$ with an amplitude of 0.156 and one at $3.27 \AA$ with an amplitude of 0.132 . Because of the absence of hydrogen-atoms on $\mathrm{O} 3$ the averages computed for the two subsets at different points on the pseudo-rotation pathway are different. The average over all conformations agrees slightly better with the experimental data than that for any single conformation. This result, however, is of scant statistical significance. A second indirect argument lies in the fact that the spectrum of calculated long nonbonded distances is sensitive to the value of $q$ but almost insensitive to variations in $\phi$. It should be emphasized that each individual $\mathrm{C} \cdot \mathrm{H}$ or $\mathrm{O} \cdots \mathrm{H}$ distance varies appreciably with $\phi$ but the spectrum as a whole is quite insensitive. Although this hampers electron-diffraction it adds another reason why THF is a good candidate for pseudorotation. During pseudo-rotation angular and torsional strain forces cancel ${ }^{1}$ and the non-bonded interactions provide little bias for one conformation over another.*

\section{EXPERIMENTA L}

A commercially available sample (Baker Analyzed Reagent) of better than $99 \%$ purity was used without further purification. Electron diffraction patterns recorded on Kodak Process plates were taken with an apparatus described previously ${ }^{3}$ equipped with an $\mathbf{r}^{3}$-rotating sector. During exposures the sample was kept at $0^{\circ}$ to ensure a vapor pressure of 30 torr. From each series of patterns taken at the three nozzle-toplate distances $(6 \cdot 5,11$ and $21 \mathrm{~cm})$ with $40 \mathrm{kV}$ electrons, four apparently flawless plates were selected for the analysis.

Absorbancies were measured on an automatic photometer with digital output. During each reading the plates were spun about their centers an integral number of revolutions. Intensities $(I)$ were obtained from the absorbancies $(A)$ according to $I=A+0.05 \mathrm{~A}^{3}$. Corrections were made to compensate for imperfections in the $\mathrm{r}^{3}$-sector.

Acknowledgement-One of us (H.J.G.) wants to express his gratitude to the United States Educational Foundation in The Netherlands for obtaining a travel grant. The research was supported by a grant from the National Science Foundation.

- Since writing the text a microwave spectroscopic study of THF has appearod in which the pseudorotational potential energy as a function of $\phi$ has been established. The $C_{2}$ conformer is about $20 \mathrm{cal} / \mathrm{mole}$ more stable than the $C_{1}$ form, indicating virtually free pseudo rotation at room temperature. $G$. G. Engerholm, A. C. Luntz, W. D. Gwinn, and D. O. Harris, Ring Puckering in 5-Membered Rings-II: The Microwave Spectrum, Dipole Moment, and Barrier to Pseudorotation in Tetrahydrofuram to be published. 


\section{REFERENCES}

1 W. J. Lafferty, D. W. Robinson, R. V. St. Louis, J. W. Russell and H. L. Strauss, J. Chem. Phys. 42, 2915 (1965).

2 J. Y. Beach, Ibid. 9, 54 (1941).

3 L. S. Bartell, K. Kuchitsu and R. J. de Neui, Ibid. 35, 1211 (1961).

4 R A. Bonham and L. S. Bartell, Ibid. 31, 702 (1959); L. S. Bartell, D. A. Kohl, B. L. Carroll and R. M. Gavin, Jr. Ibid. 42, 3079 (1965).

${ }^{3}$ R. A. Bonham and L. S. Bartell, J. Am. Chem. Soc. 81, 3491 (1959).

${ }^{6}$ K. Kuchitsu and L. S. Bartell, J. Chem. Phys. 35, 1945 (1961).

7 J. A. Ibers and J. A. Hoerni, Acta Cryst. 7, 405 (1954).

- J. E. Kilpatrick, K. S. Pitzer and R. Spitzer, J. Am. Chem. Soc. 69, 2483 (1947); Ibid. 80, 6697 (1958). K. S. Pitzer and W. E. Donath, Ibid. 81, 3213 (1959).

9 W. J. Adams, H. J. Geise and L. S. Bartell, A.C.S. Meeting. Columbus, Ohio (1968). 